\title{
Ferroelectric Instability and Dimensionality in Bi-Layered Perovskites and Thin Films
}

\author{
Akira Onodera, Masanori Fukunaga, and Masaki Takesada \\ Department of Physics, Hokkaido University, Sapporo 060-0810, Japan \\ Correspondence should be addressed to Akira Onodera, onodera@phys.sci.hokudai.ac.jp \\ Received 25 May 2012; Accepted 3 August 2012 \\ Academic Editor: Biljana Stojanovic \\ Copyright () 2012 Akira Onodera et al. This is an open access article distributed under the Creative Commons Attribution License, \\ which permits unrestricted use, distribution, and reproduction in any medium, provided the original work is properly cited.
}

The dielectric and thermal properties of Bi (bismuth)-layered perovskite $\mathrm{SrBi}_{2} \mathrm{Ta}_{2} \mathrm{O}_{9}$ (SBT) are discussed in comparison with ferroelectric thin $\mathrm{BaTiO}_{3}$ films. Although these two perovskites exhibit quite a different nature, the dielectric properties of $\mathrm{BaTiO}_{3}$ thin film are similar to those in bulk SBT. The dielectric properties and pseudo-two-dimensional structure between SBT and thin film suggest that the bulk layered ferroelectric SBT is a good model of ultra-thin ferroelectric film with two perovskite layers, free from any misfit lattice strain with substrate and surface charge at the interface with electrodes. Based on the mechanism of ferroelectric phase transition of SBT, it seems plausible that the ferroelectric interaction is still prominent but shows a crossover from ferroelectric to antiferroelectric interaction in perovskite ultra-thin films along the tetragonal axis.

\section{Introduction}

Barium titanate $\left(\mathrm{BaTiO}_{3}\right)$ is a well-known ferroelectric with perovskite structure, which has been considered to be a prototype for many oxide ferroelectrics. The dielectric constant $(\varepsilon)$ follows a well-known Curie-Weiss law, $\varepsilon=\mathrm{C}$ / $\left(T-T_{c}\right)$, and shows a large dielectric anomaly at $T_{c}(409 \mathrm{~K})$, which has been explained by the concept of soft mode by Cochran [1, 2]. Recently, however, it has been recognized that the dielectric constant begins to decrease with decreasing the sample thickness, and shows broad and non-Curie-Weiss behavior. This evidence indicates that the well-established soft mode may be modified in the treatment of lattice dynamics of thin films of $\mathrm{BaTiO}_{3}$, if the LST (Lyddane-SachsTeller) relation

$$
\frac{\varepsilon}{\varepsilon_{\infty}}=\prod_{j}\left(\frac{\omega_{L j}^{2}}{\omega_{T j}^{2}}\right),
$$

holds even in thin films as well as in bulk crystals. Furthermore, the anomalous part of specific heat $\left(\Delta C_{p}\right)$ changes to a very broad and unclear one in thin $\mathrm{BaTiO}_{3}$ films, while it is sharp and large at $T_{c}$ in bulk crystals. This suggests that the temperature dependence of an order parameter $\eta_{s}$ (the spontaneous polarization $P_{s}$ in the case of ordinary ferroelectrics) plays somewhat in different manners as the usual mean-field behavior known in typical ferroelectrics, because $\eta_{s}$ is related to $\Delta C_{p}$ in the mean field theory as

$$
\eta_{s}^{2}(T)=\frac{C}{2 \pi} \int_{T}^{\infty} \frac{\Delta C_{p}}{T} d T
$$

As pointed out by many researches, these novel ferroelectric properties are considered to be essentially due to the twodimensionality in thin films.

On the other hand, the similar novel dielectric behavior has been found in layered perovskite compounds. $\mathrm{SrBi}_{2} \mathrm{Ta}_{2} \mathrm{O}_{9}$ (SBT) has been extensively studied as a candidate for ferroelectric nonvolatile memory devices [3-5]. SBT has a pseudo-two-dimensional crystal structure with two $\mathrm{TaO}_{6}$ perovskite groups sandwiched by $\mathrm{Bi}_{2} \mathrm{O}_{2}$ semiconducting layers along the pseudotetragonal $c$ axis within the unit cell. SBT undergoes a ferroelectric phase transition at $608 \mathrm{~K}$, while the dielectric anomaly and anomalous specific heat are small in comparison with $\mathrm{BaTiO}_{3}$. This similarity of crystal structures and dielectric properties between $\mathrm{BaTiO}_{3}$ thin films and layered perovskite SBT shows that both materials have a common mechanism resulted in dielectric nature as discussed in the following section. Moreover, it suggests that SBT may be a good model for an ideal ferroelectric ultra-thin 


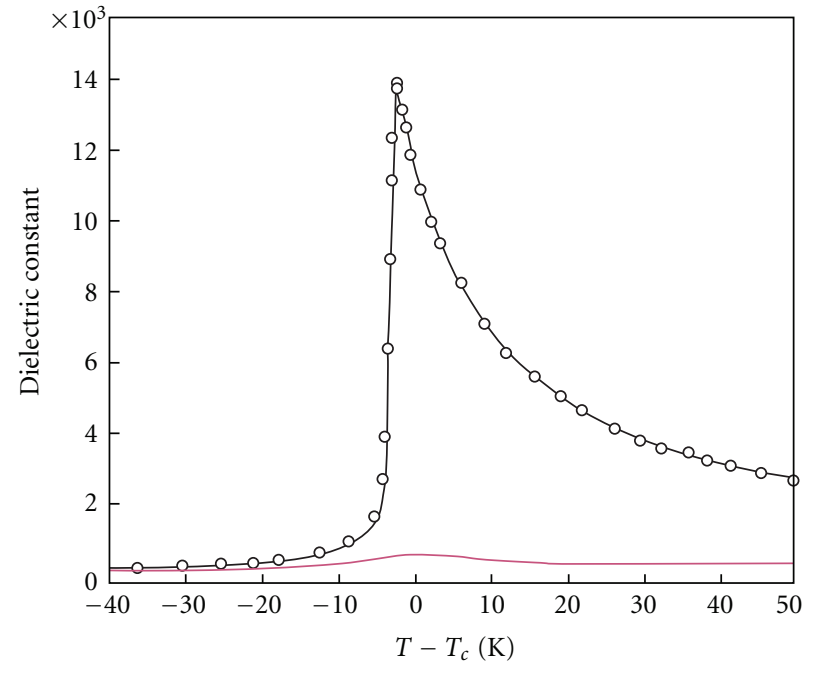

(a)

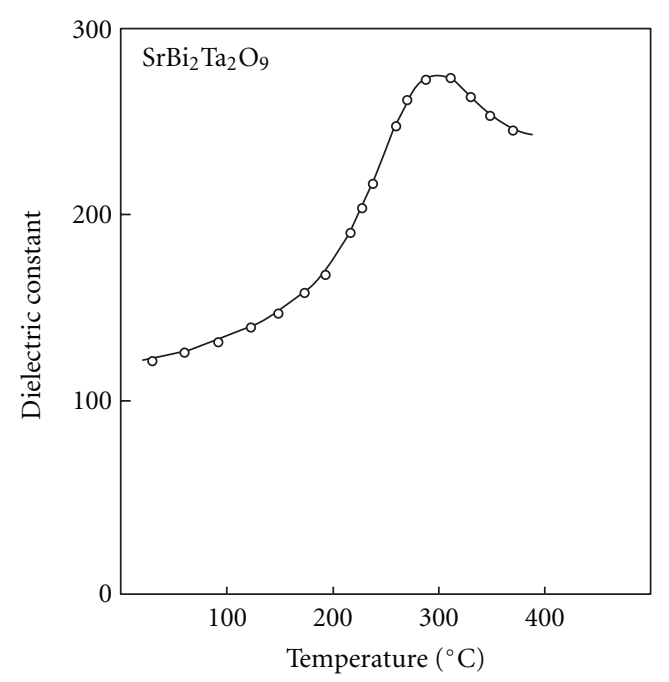

(b)

FIgURE 1: Temperature dependence of dielectric constant of (a) $\mathrm{BaTiO}_{3}$ (black line) and $\mathrm{SrBi}_{2} \mathrm{Ta}_{2} \mathrm{O}_{9}$ (red line) and (b) that of an expanded figure in $\mathrm{SrBi}_{2} \mathrm{Ta}_{2} \mathrm{O}_{9}[6]$.

film with two perovskite unit cells, though SBT itself is a bulk crystal. In this paper, we will discuss the ferroelectric nature and stability in ultra-thin films on the basis of ferroelectric properties of Bi-layered perovskites.

\section{Dielectric and Thermal Properties in $\mathrm{BaTiO}_{3}$ and $\mathrm{SrBi}_{2} \mathrm{Ta}_{2} \mathrm{O}_{9}$}

The temperature dependence of $\varepsilon$ of $\mathrm{BaTiO}_{3}$ and SBT is compared in Figure 1 as a function of $\left(T-T_{c}\right)$ for simplicity, where $T_{c}$ is a ferroelectric phase transition temperature of each perovskite, SBT, and $\mathrm{BaTiO}_{3}$. The large CurieWeiss dielectric anomaly associated with ferroelectric phase transition was noticed in $\mathrm{BaTiO}_{3}$ at $T_{\mathcal{c}}$, while a broad nonCurie-Weiss behavior was observed in layered perovskite SBT $[6,8-14]$. The half temperature widths of dielectric anomalies are $10 \mathrm{~K}$ for $\mathrm{BaTiO}_{3}$ and about $400 \mathrm{~K}$ for SBT, respectively. The spontaneous polarization $\left(P_{s}\right)$ of SBT is relatively large $\left(5.8 \sim 10 \mu \mathrm{C} / \mathrm{cm}^{2}\right.$ along the $a$ axis at room temperature), while $P_{s}=26 \mu \mathrm{C} / \mathrm{cm}^{2}$ in $\mathrm{BaTiO}_{3}$ along the tetragonal $c$ axis. As $P_{s}$ in SBT is the same order as those in order-disorder ferroelectrics, we expect that $\varepsilon$ obeys the Curie-Weiss law and the peak value of $\varepsilon$ is the order of several thousands. However, we could only observe a round peak of about 300 and weak temperature dependency around $608 \mathrm{~K}\left(T_{c}\right)$ in SBT. It is interesting to point out that similar diffuse and round dielectric anomalies were observed in ferroelectric thin films. In $\mathrm{BaTiO}_{3}$ epitaxial thin films, diffuse dielectric anomaly was reported by Yoneda et al. [7, 15-18]. Thin films of $\mathrm{BaTiO}_{3}$ showed a small and broad dielectric anomaly as shown in Figure 2. The peak value of $\varepsilon$ is 1400 for $4000 \AA$ thick film, and only 370 for $1000 \AA$ thick film. This similarity of dielectric properties suggests the existence of some common mechanism between SBT bulk crystal and

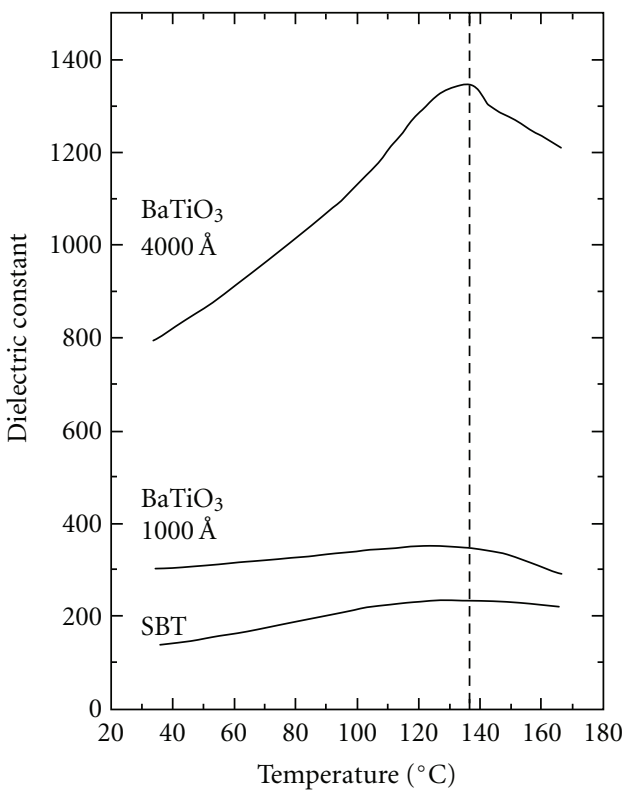

FIgURE 2: Temperature dependence of dielectric constant of SBT and $\mathrm{BaTiO}_{3}$ epitaxial thin films on $\mathrm{SrTiO}_{3}$ with $4000 \AA$ and $1000 \AA$ [7].

$\mathrm{BaTiO}_{3}$ thin film. Recently, Tagantsev et al. discussed a twodimensional strain effect on dielectric constant in perovskite ferroelectric thin films and reported a diffuse dielectric anomaly [19].

Thermal anomaly associated with the phase transition is also diffuse and widely spread in SBT as shown in Figure $3[8,10]$, while a sharp and large anomaly was found at $T_{c}$ in bulk $\mathrm{BaTiO}_{3}$ (Figure 4) [20]. However, the specific heat of $\mathrm{BaTiO}_{3}$ epitaxial films shows diffuse temperature 


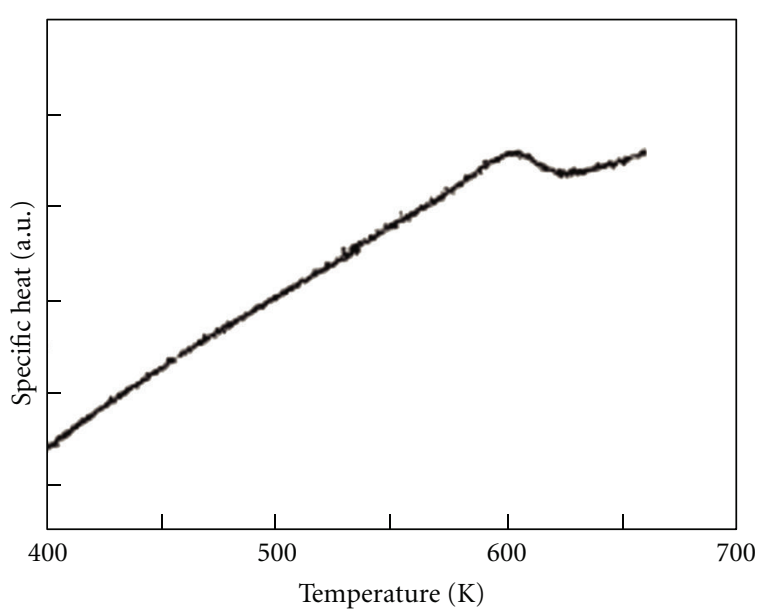

Figure 3: Temperature dependence of specific heat of $\mathrm{SrBi}_{2} \mathrm{Ta}_{2} \mathrm{O}_{9}$ single crystal [8].

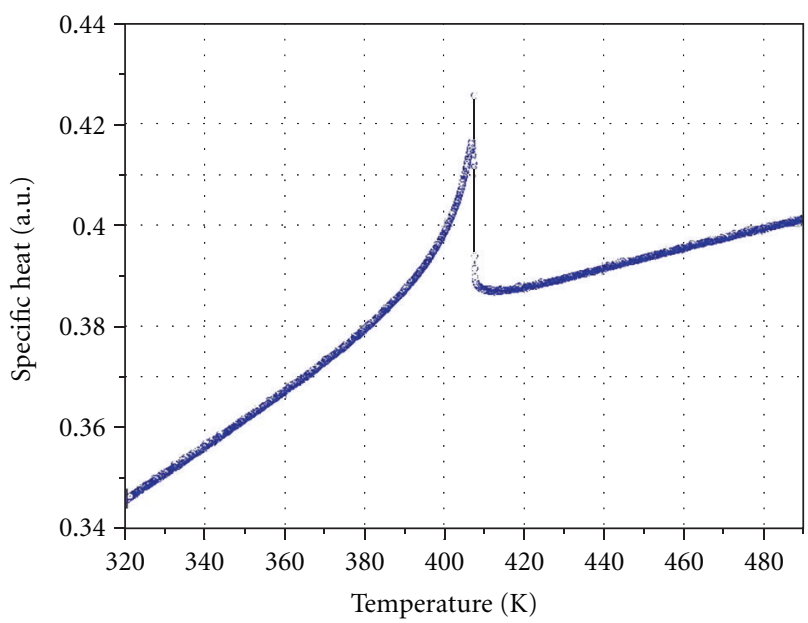

Figure 4: Temperature dependence of specific heat of $\mathrm{BaTiO}_{3}$ single crystal around the paraelectric-ferroelectric phase transition point $T_{c}[20]$.

dependence (Figure 5) just as those in SBT [21]. With decreasing thickness of epitaxial films of $\mathrm{BaTiO}_{3}$, the shape of anomalous part of specific heat becomes round and diffuse and exhibits thermal hysteresis in those with $2000 \AA$ and $60 \AA$. In $\mathrm{BaTiO}_{3}$ polycrystalline thin films, a rather sharp anomaly was reported $[22,23]$. The diffuse dielectric and thermal behavior observed around $T_{c}$ may be attributed to the two-dimensional effect in SBT and $\mathrm{BaTiO}_{3}$ epitaxial thin films.

\section{Structural Analogy: Pseudo-Two-Dimensionality}

$\mathrm{BaTiO}_{3}$ has a prototype cubic crystal structure of perovskite in the paraelectric high-temperature phase (space group Pm $3 \mathrm{~m}$, with lattice parameter $a=3.996 \AA$ at $393 \mathrm{~K})$. It changes to tetragonal (space group P4 mm, $a=3.992, c=$ $4.036 \AA$ at r. t.) associated with the paraelectric-ferroelectric phase transition. The unit cell contains one $\mathrm{TiO}_{6}$ octahedron at the center and $\mathrm{Ba}$ ions locate at the corners. The $\mathrm{TiO}_{6}$ octahedron is tightly bonded with each other and generally considered as a hard unit, which has a regular octahedral form in the paraelectric phase. According to Slater, the correlation along the -O-Ti-O-Ti-O- chain is very strong along the tetragonal $c$ axis and the small octahedral distortion results in ferroelectricity below $T_{c}$ [26]. Epitaxial $\mathrm{BaTiO}_{3}$ films were grown by on $\mathrm{SrTiO}_{3}$ and $\mathrm{MgO}$ substrates using the activated reaction evaporation method, which were characterized by $\mathrm{X}$-ray diffraction as shown in Figure $6[24,27]$. Only the $(00$ l) reflections were observed. The submaximum peaks of the Laue function were observed around the fundamental peaks of the (llll $\left.\begin{array}{lll}0 & 1\end{array}\right),\left(\begin{array}{lll}0 & 0 & 2\end{array}\right),\left(\begin{array}{lll}0 & 0 & 3\end{array}\right)$, and ( $\left.\begin{array}{lll}0 & 0 & 4\end{array}\right)$. The strong peaks denoted as "Sub" in Figure 6 mean the $\left(\begin{array}{lll}0 & 0 & l\end{array}\right)$ reflections from the $\mathrm{SrTiO}_{3}$ substrate. This evidence indicates that this film is an epitaxial crystal with a perovskite structure. Two films with thickness of $2000 \AA$ and $60 \AA$ were used for the specific heat measurements. The heat capacity was measured using an a. c. calorimeter.

$\mathrm{SrBi}_{2} \mathrm{Ta}_{2} \mathrm{O}_{9}$ is a $\mathrm{Bi}$-layered perovskite oxide with a highly anisotropic structure, where perovskite-type $\left[\mathrm{SrTa}_{2} \mathrm{O}_{7}\right]^{2-}$ groups and semiconducting $\left[\mathrm{Bi}_{2} \mathrm{O}_{2}\right]^{2+}$ layers are stacked alternately along the pseudo-tetragonal $c$ axis as shown in Figure 7. The general chemical formula of Bi-layered perovskite oxides with stacking number $(m)$ of octahedral $\mathrm{BO}_{6}$ perovskite groups is given as $\left(\mathrm{Bi}_{2} \mathrm{O}_{2}\right)^{2+}\left(A_{m-1} B_{m} O_{3 m+1}\right)^{2-}$, where $A=\mathrm{Na}^{+}, \mathrm{K}^{+}, \mathrm{Ba}^{2+}, \mathrm{Ca}^{2+}, \mathrm{Pb}^{2+}, \mathrm{Sr}^{2+}, \mathrm{Bi}^{3+}, B=\mathrm{Fe}^{3+}$, $\mathrm{Ti}^{4+}, \mathrm{Nb}^{5+}, \mathrm{Ta}^{5+}, \mathrm{W}^{6+}$, and $m=1$ to 6. Many of these compounds are ferroelectric with high transition temperatures. Ferroelectricity in SBT with $m=2$ was discovered below $608 \mathrm{~K}\left(T_{c}\right)$ by Smolenskii et al. in 1961 [6]. The crystal structure of SBT is orthorhombic at $r$. $t$. with space group $\mathrm{A} 2_{1}$ am $(a=5.531, b=5.534, c=25.984 \AA)$. The lattice is highly anisotropic and pseudo-two-dimensional, and the -O-Ta-O-Ta-O- linkage along the pseudo-tetragonal $c$ axis is interrupted by the existence of semiconducting $\mathrm{Bi}_{2} \mathrm{O}_{2}$ layers in SBT $[11,14,25]$. SBT undergoes two successive phase transitions at $608 \mathrm{~K}$ and $850 \mathrm{~K}$. The high-temperature paraelectric phase is tetragonal with space group $\mathrm{I} 4 \mathrm{mmm}$, $a=3.927$, and $c=25.142 \AA$ at $1000 \mathrm{~K}$, where the $\mathrm{TaO}_{6}$ octahedra take antiparallel arrangements along the tetragonal $c$ axis. The crystal structures of the ferroelectric $(300 \mathrm{~K})$ and paraelectric phases $(1000 \mathrm{~K})$ were determined by X-ray diffraction as summarized in Tables 1 and 2. X-ray diffraction profile was given in Figure 8 [25].

The shape of $\mathrm{TaO}_{6}$ octahedron is not perfect and is still distorted even in the paraelectric phase along the $c$ axis. The Ta-O bond length owned commonly by adjacent octahedra normal to the pseudo-tetragonal $c$ axis is a little bit short and that of $\mathrm{O}$ directed to $\mathrm{Bi}_{2} \mathrm{O}_{2}$ layer is long. In the ferroelectric phase, this crystal favors canted octahedral arrangements below $T_{c}$, which results in the net spontaneous polarization along the $a$-axis.

\section{Ferroelectricity}

Ferroelectricity in Bi-layered perovskite $\mathrm{SrBi}_{2} \mathrm{Ta}_{2} \mathrm{O}_{9}$ (SBT) does not appear along the pseudo-tetragonal $c$ axis but along 


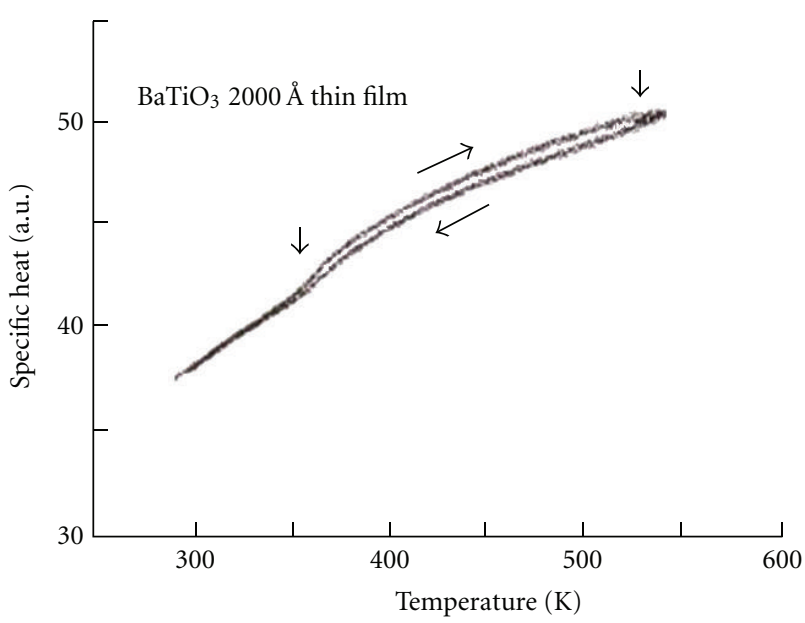

(a)

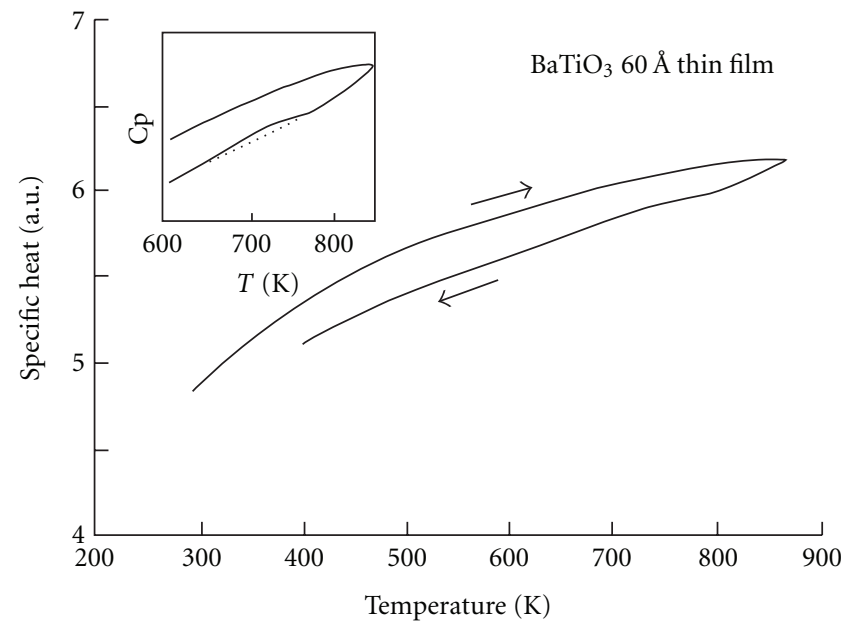

(b)

Figure 5: Temperature dependence of specific heat of $\mathrm{BaTiO}_{3}$ epitaxial thin films on $\mathrm{SrTiO}_{3}$ substrate; (a) $2000 \AA$ thick and (b) $60 \AA$ thick. The arrows show the direction of heating and cooling. The sharp anomalous specific heat in the single crystal changes to diffuse one in thin films [21].

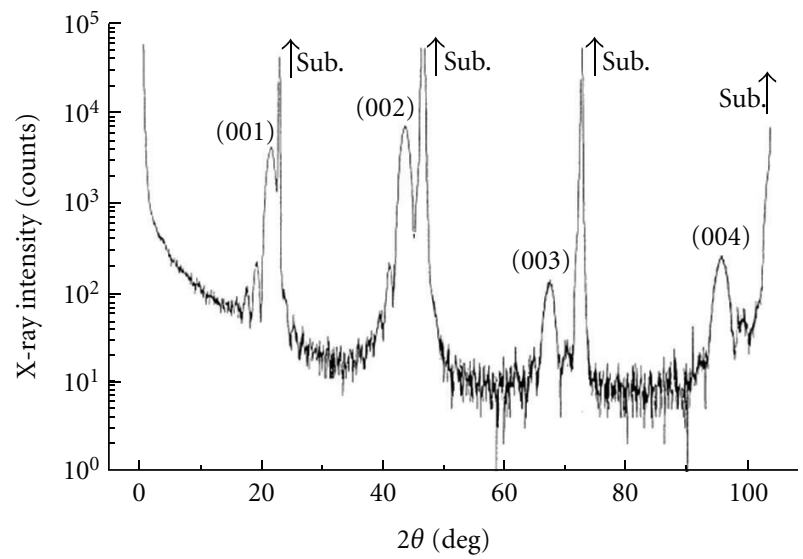

Figure 6: X-ray diffraction profiles along the $\left[\begin{array}{lll}0 & 0 & l\end{array}\right]$ direction of the $\mathrm{BaTiO}_{3}$ thin films with $60 \AA$ on $\mathrm{SrTiO}_{3}$ substrate (monochromatized $\mathrm{CuK} \alpha$ ). Subscript "Sub" means reflections from $\mathrm{SrTiO}_{3}$ substrate [24].

TABle 1: Positional and thermal parameters of ferroelectric phase $\left(\mathrm{A} 2_{1} \mathrm{am}\right)$ of $\mathrm{SrBi}_{2} \mathrm{Ta}_{2} \mathrm{O}_{9}$ at $300 \mathrm{~K}$ [25].

\begin{tabular}{lcccc}
\hline Atom & $x$ & $y$ & $z$ & $B_{\text {eq }}$ \\
\hline $\mathrm{Sr}$ & 0 & 0.2610 & 0 & $0.69(1)$ \\
$\mathrm{Bi}$ & $0.4833(14)$ & $0.7738(4)$ & $0.2011(1)$ & $1.77(1)$ \\
$\mathrm{Ta}$ & $0.5177(16)$ & $0.7468(6)$ & $0.4143(1)$ & $0.37(1)$ \\
$\mathrm{O}(1)$ & $0.5365(89)$ & $0.3335(67)$ & 0 & $1.04(5)$ \\
$\mathrm{O}(2)$ & $0.4904(72)$ & $0.7316(49)$ & $0.3402(4)$ & $1.55(4)$ \\
$\mathrm{O}(3)$ & $0.7057(76)$ & $0.0146(130)$ & $0.2623(5)$ & $0.85(4)$ \\
$\mathrm{O}(4)$ & $0.7523(94)$ & $0.0002(101)$ & $0.0730(6)$ & $0.62(5)$ \\
$\mathrm{O}(5)$ & $0.7854(87)$ & $0.9744(93)$ & $0.5850(6)$ & $0.91(4)$ \\
\hline
\end{tabular}

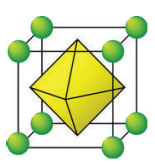

(a)

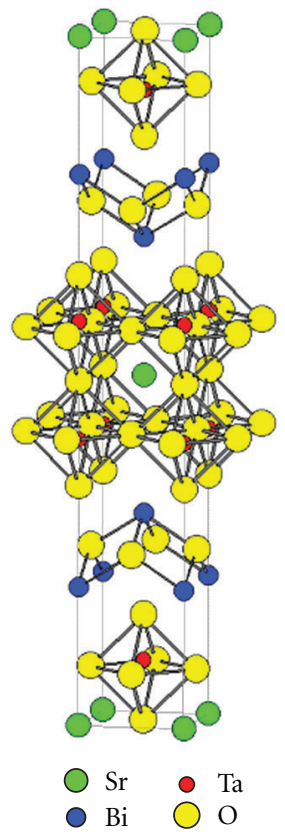

(b)
FIGURE 7: Crystal structure of (a) fundamental perovskite and (b) Bi-layered perovskite $\mathrm{SrBi}_{2} \mathrm{Ta}_{2} \mathrm{O}_{9}$ (upper half of the unit cell) [11, 25].

the $a$ axis normal to the pseudo-tetragonal axis, while along the tetragonal $c$ axis in $\mathrm{BaTiO}_{3}$. The crystal structure is highly anisotropic along the pseudo-tetragonal $c$ axis and the single crystal of SBT has easily cleaved along the pseudo-tetragonal $c$ axis, as the semiconducting $\mathrm{Bi}_{2} \mathrm{O}_{2}$ layer connects weakly upper and lower perovskite groups by van der Waals interaction. Crystal structure analysis of SBT shows that $\mathrm{TaO}_{6}$ 


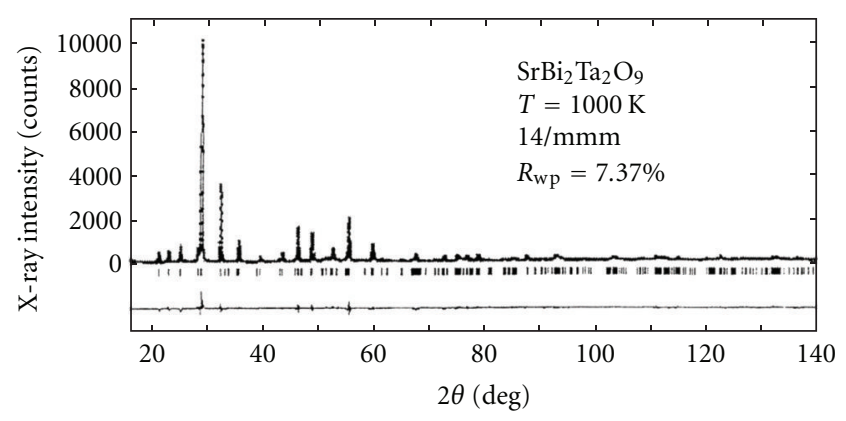

Figure 8: X-ray diffraction patterns of $\mathrm{SrBi}_{2} \mathrm{Ta}_{2} \mathrm{O}_{9}(\mathrm{CuK} \alpha)$ at $1000 \mathrm{~K}[25]$.

TABle 2: Positional and thermal parameters of the paraelectric phase (I4/mmm) $\mathrm{SrBi}_{2} \mathrm{Ta}_{2} \mathrm{O}_{9}$ at $1000 \mathrm{~K}$ [25].

\begin{tabular}{llccc}
\hline Atom & $x$ & $y$ & $z$ & $B_{\mathrm{eq}}(A)$ \\
\hline $\mathrm{Sr}$ & 0 & 0 & 0 & $1.09(1)$ \\
$\mathrm{Bi}$ & 0 & 0 & $0.2007(1)$ & $3.41(1)$ \\
$\mathrm{Ta}$ & 0 & 0 & $0.4140(1)$ & $0.05(1)$ \\
$\mathrm{O}(1)$ & 0 & 0.5 & 0.25 & $0.8(6)$ \\
$\mathrm{O}(2)$ & 0 & 0 & 0.5 & $1.41(5)$ \\
$\mathrm{O}(3)$ & 0 & 0.5 & $0.0756(3)$ & $0.75(4)$ \\
$\mathrm{O}(4)$ & 0 & 0 & $0.3479(5)$ & $1.17(4)$ \\
\hline
\end{tabular}

octahedra are still distorted along the pseudo-tetragonal $c$ axis, and locate in antiparallel way even in the hightemperature paraelectric phase above $850 \mathrm{~K}$. Although the -O-Ta-O-Ta-O- chain along the pseudo-tetragonal $c$ axis is interrupted by the existence of semiconducting $\mathrm{Bi}_{2} \mathrm{O}_{2}$ layers, this evidence indicates the strong interaction to displace along the $c$ axis exists and the strongly correlated -O-Ta-O$\mathrm{Ta}-\mathrm{O}$ - chain should play an essential role for the appearance of ferroelectricity in SBT as those in $\mathrm{BaTiO}_{3}$ [26]. In the hightemperature paraelectric phase, total polarization cancels by the antiparallel arrangement of octahedra, since $\mathrm{TaO}_{6}$ is not perfect octahedron but elongates along the $c$ axis; this indicates SBT is antiferroelectric above $850 \mathrm{~K}$. In the ferroelectric phase, this crystal favors canted octahedral arrangements below $T_{c}$, which results in the net spontaneous polarization along the $a$ axis. As this situation is just the same as those reported in the case of weak ferromagnetism in magnetic materials, we suggest canted ferroelectricity (weak ferroelectricity) for SBT.

On the other hand, this pseudo-two-dimensional character of crystal structure is just suitable for fabrication of thin films. The spontaneous polarization $\left(P_{s}\right)$ is relatively large (5.8 $\sim 10 \mu \mathrm{C} / \mathrm{cm}^{2}$ along the $a$ axis at room temperature), while $P_{s}=26 \mu \mathrm{C} / \mathrm{cm}^{2}$ in a representative perovskite ferroelectric $\mathrm{BaTiO}_{3}$ along the tetragonal $c$ axis.

It should be noticed that these two perovskite oxides exhibit quite different dielectric nature. However, it is very interesting to point out the similarity in dielectric properties between $\mathrm{BaTiO}_{3}$ thin films and SBT bulk crystals, since $\mathrm{BaTiO}_{3}$ thin ferroelectric films exhibit diffuse dielectric anomaly.

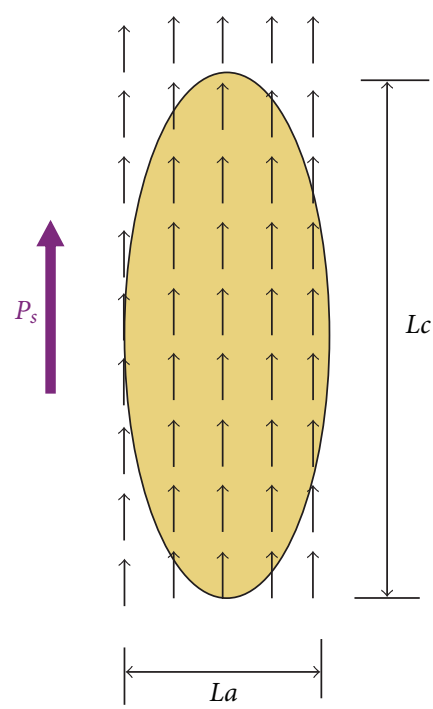

FIGURE 9: Ferroelectric correlation region in dipolar materials [28].

\section{Size Effect in Ferroelectric Thin Films}

Ferroelectricity appears due to a delicate balance between long-range dipole-dipole interaction along the polar axis and short-range interaction. The typical dipolar correlation lengths for many ferroelectrics are $L c=100 \sim 500 \AA$ along the polar axis and $L a=10 \sim 20 \AA$ normal to the polar axis [28]. The needle-shaped correlation region is sketched in Figure 9, where $L a$ is several unit cells, of the same order as the thickness of a $180^{\circ}$ domain wall, and $L c$ is about $25 \sim$ 125 unit cells in the case of $\mathrm{BaTiO}_{3}$. Therefore, it should be reasonable to consider that the stability of the ferroelectricity may be suppressed by decreasing the thickness of the thin films.

Measurements of thickness dependence of ferroelectricity are generally not so easy, because of difficulties in preparation of good quality of thin films, and additional surface effects such as depolarization fields, space-charge effects, and misfit strain between film and substrate. These effects essentially influence the ferroelectric behavior in thin films. Many attempts have been reported to study the thickness dependence of ferroelectric properties of ferroelectric thin films prepared by vacuum evaporation, sputtering techniques, chemical vapor deposition, and so on.

Tybell, Ahn, and Triscone have examined the possibility of the existence of a critical thickness and showed the detection of the ferroelectricity in perovskite $\mathrm{Pb}\left(\mathrm{Zr}_{0.2} \mathrm{Ti}_{0.8}\right)_{3}$ films down to a thickness of 10 unit cells (40 $\AA$ ) [37]. Bune et al. reported ferroelectric activity in ferroelectric polymer films with thickness of two layers $(10 \AA)$ and the near absence of finite-size effects in these two-dimensional ferroelectrics which may be generated by coupling only within the plane of the film [38]. Recent $A b$ initio studies have confirmed the possibility of retaining the ferroelectricity in ultra-thin films, and suggested the absence of the critical size effect $[39,40]$.

On the other hand, Junquera and Ghosez reported firstprinciple calculations on a realistic model of perovskite thin 
TABLE 3: Estimated dipole moment of $\mathrm{TaO}_{6}$ octahedron of the ferroelectric phase at $300 \mathrm{~K}\left(\mathrm{~A} 2_{1} \mathrm{am}\right)$ and the high-temperature paraelectric phase $(\mathrm{I} 4 / \mathrm{mmm})$ at $1000 \mathrm{~K}[25]$.

\begin{tabular}{lccccc}
\hline & & \multicolumn{2}{c}{ A2 ${ }_{1}$ am } & & I4/mmm \\
& Present study & Miura [34] & Shimakawa et al. [35] & Rae et al. [36] & 0.386 \\
Present study \\
\hline$p_{x}$ & 0.035 & 0.564 & 0.425 & 0.003 & 0 \\
$p_{y}$ & -0.702 & -0.074 & 0.001 & 1.117 & 0 \\
$p_{z}$ & 1.528 & 1.747 & 1.169 & 1.182 & 1.365 \\
$p$ & 1.682 & 1.837 & 1.244 & & 1.365 \\
\hline
\end{tabular}

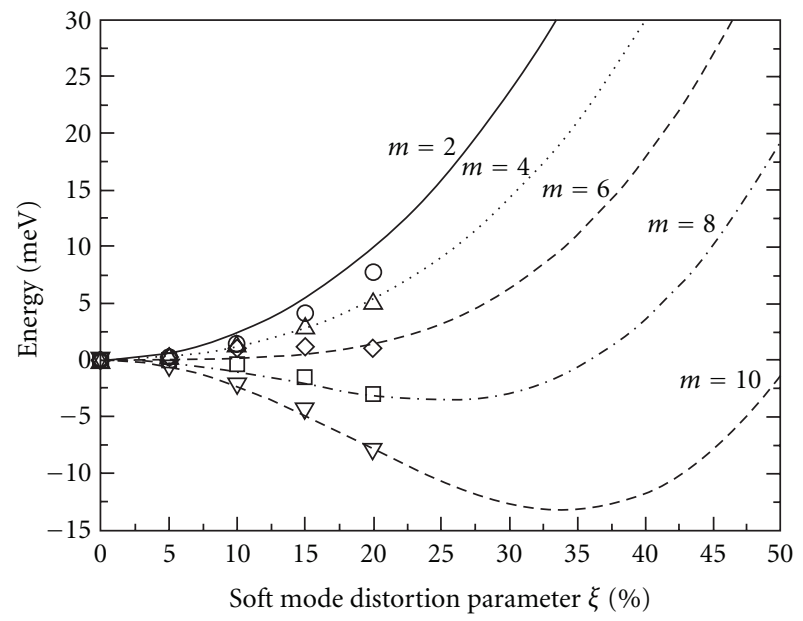

Figure 10: First-principles calculations of the energy of $\mathrm{BaTiO}_{3}$ ferroelectric films with $m$ unit cells as a function of the soft-mode distortion $\xi$ [29].

films with metallic electrodes. They showed that $\mathrm{BaTiO}_{3}$ films with $\mathrm{SrRuO}_{3}$ electrodes have the critical thickness of 6 unit cells $(\sim 24 \AA)$ and lose the ferroelectricity below this thickness, due to the depolarization field effect at the ferroelectric-metal interfaces (Figure 10) [29].

Recent Raman scattering studies showed that ultra-thin $\mathrm{BaTiO}_{3}$ films grown commensurately on $\mathrm{SrTiO}_{3}$ substrates have a spontaneous polarization as thin as 4 unit cells (16 $\AA$ ) [30]. The ferroelectric phase transition temperature $T_{c}$ are shown as a function of $\mathrm{BaTiO}_{3}$ film thickness in Figure 11. Recent experimental and theoretical works showed the critical thickness is much smaller than those previously reported.

\section{Mechanism of Phase Transition in SBT}

It should be pointed out the close analogy of ferroelectric behavior between Bi-layered perovskite $\mathrm{SrBi}_{2} \mathrm{Ta}_{2} \mathrm{O}_{9}$ (SBT) and thin film of the so-called typical ferroelectric perovskite $\mathrm{BaTiO}_{3}$. The crystal structures of the high-temperature paraelectric phase at $1000 \mathrm{~K}$ and the ferroelectric phase at r. t. are schematically shown in Figure 10 [25]. The $\mathrm{TaO}_{6}$ octahedra are distorted in both phases. Even in the high-temperature paraelectric phase, the octahedra are elongated along the pseudo-tetragonal $c$ axis and locate in an antiparallel way.

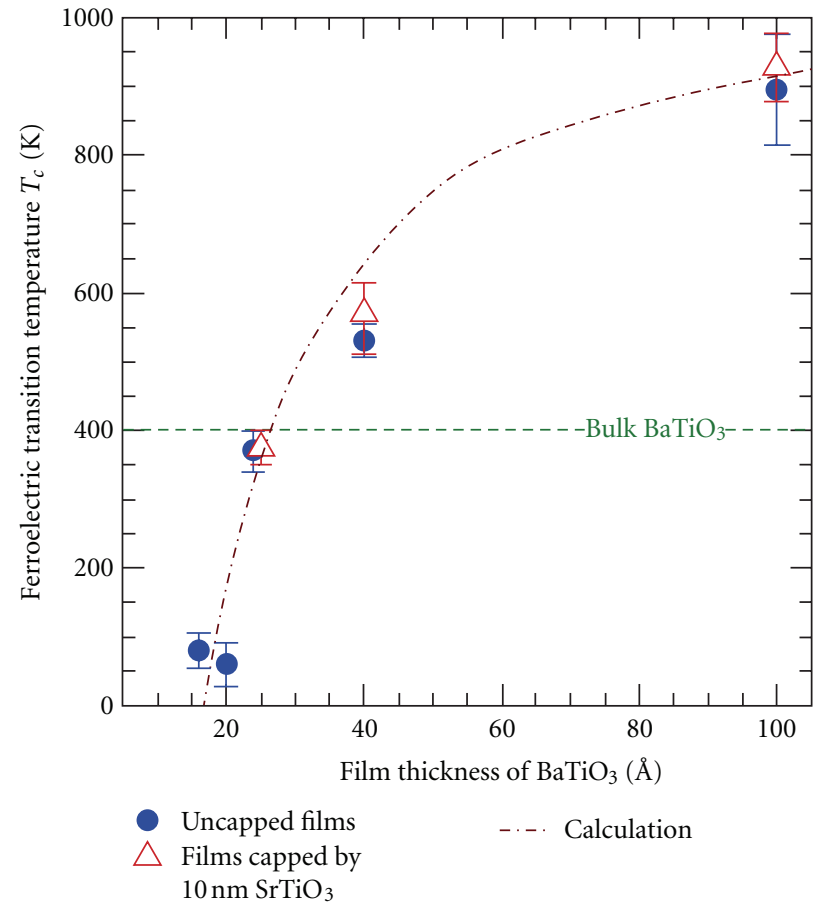

FIGURE 11: The plot of the ferroelectric phase transition temperature $T_{c}$ versus film thickness of $\mathrm{BaTiO}_{3}$ films grown on $\mathrm{SrTiO}_{3}$ substrates, observed by Raman scattering [30].

The distortion parameter of one $\mathrm{TaO}_{6}$ octahedron, $p$, defined as

$$
p=|\mathbf{p}|=\sum_{i=1}^{7} q_{i}\left(\mathbf{r}_{i}-\mathbf{r}_{G}\right),
$$

is estimated to be 1.365 debye along the $c$ axis as shown in Table 3, where $q_{i}$ and $\mathbf{r}_{i}$ are charge and position of each constituent ion, and $\mathbf{r}_{G}$ is the gravity center of $\mathrm{TaO}_{6}$. The parameter $\mathbf{p}$ is obtained as $(0,0,1.365)$ in debye unit in the high-temperature paraelectric phase. In the ferroelectric phase, the absolute value is 1.682 debye, which is almost the same as that of the high-temperature paraelectric phase within errors. If the distortion of octahedron corresponds to a dipole moment, it should be probable that SBT prefers an antiferroelectric structure along the $c$-axis, when the distorted octahedra are mainly responsible for the ferroelectric activity. Furthermore, these distorted octahedra have a canted arrangement in the ferroelectric phase as shown in Figure 12. 


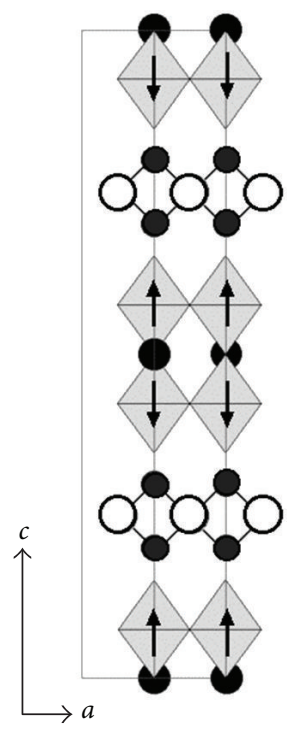

(a)

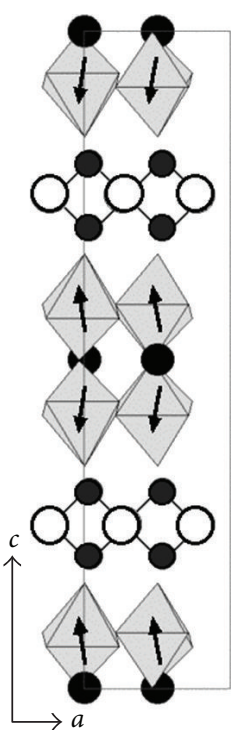

(b)

Figure 12: Crystal structures of (a) the paraelectric and (b) the ferroelectric phases of layered perovskite $\mathrm{SrBi}_{2} \mathrm{Ta}_{2} \mathrm{O}_{9}$. Arrows show estimated dipole arrangements of $\mathrm{TaO}_{6}$ octahedra [25].

These structural arrangements of $\mathrm{TaO}_{6}$ octahedra in SBT remind us of a canted-ferromagnet (or weak ferromagnet) discussed by Moriya [41] and in layered canted-ferromagnets by de Gennes [42]. The free energy is given in terms of sublattice polarizations $P_{1}, P_{2}$, and an angle $\theta$ between them as

$$
F=\frac{1}{2} \alpha_{1} P_{1}^{2}+\frac{1}{2} \alpha_{2} P_{2}^{2}+g P_{1} P_{2} \cos \theta-\delta P_{1} P_{2} \sin \theta,
$$

where the third symmetrical term is a well-known exchange interaction and the last term is an antisymmetric Dzialoshinski-Moriya interaction. If $\theta=\pi$ and $\alpha_{1}=\alpha_{2}$, the above expression is just the same as that for antiferroelectrics proposed by Kittel [43]. The last term favors the canted arrangement of dipoles rather than antiferroelectric one. From the condition, $\partial F / \partial \theta=0$, we get the following relation:

$$
\tan \theta=-\frac{\delta}{g} .
$$

As the observed value of $\theta$ is $154^{\circ}$, the coefficient $\delta$ of the antisymmetric term is about half of the symmetric one $g$. From the relations

$$
\frac{\partial F}{\partial P_{1}}=\frac{\partial F}{\partial P_{2}}=E,
$$

we have the expression for the dielectric susceptibility as

$$
\chi=\frac{2}{\left(\alpha+g^{\prime}\right)}
$$

where

$$
g^{\prime}=g \cos \theta-\delta \sin \theta
$$

when we assume $\alpha_{1}=\alpha_{2}=\alpha$. It is evident that the dielectric susceptibility shows small anomaly just like antiferroelectric one, which may be smeared by two-dimensional surface strain as pointed out by Tagantsev et al. [19]. Because of the term of the Dzialoshinski-Moriya interaction, the ferroelectric phase transition will be realized in SBT, and the characteristic weak dielectric properties may be explained. The asymmetric interaction may be attributed to the twodimensional effect in SBT and $\mathrm{BaTiO}_{3}$ epitaxial thin films.

The decrease and nonclear behavior of dielectric constant were also observed around $T_{c}$ with decreasing film thickness in $(\mathrm{Ba}, \mathrm{Sr}) \mathrm{TiO}_{3}$ thin films. In this case, Hwang analyzed this decrease by considering the effects of a finite chargescreening length of metal electrodes and an intrinsic dead layer of the surface [44]. The layered ferroelectric SBT is a bulk crystal itself, and is considered to be an example of ultra-thin ferroelectric model with two perovskite layers, free from any misfit lattice strain and interface charge layer with electrodes.

It should be pointed out that the ferroelectricity of perovskite thin films with two unit cells may be stable even in those with $m=2$, although its polarization does not appear along the tetragonal axis but along the axis normal to the tetragonal axis (within layer). Therefore, there is a crossover of ferroelectric to antiferroelectric interaction along the tetragonal axis, with decreasing the stacking number of perovskite units. Furthermore, the ultra-thin films prefer an antiferroelectric structure rather than a ferroelectric structure in thin films.

\section{Soft Mode in Bi-Layered Perovskite}

Measurements of the soft mode of SBT have been reported by Raman scattering as shown in Figure 13 [31, 32, 45]. 


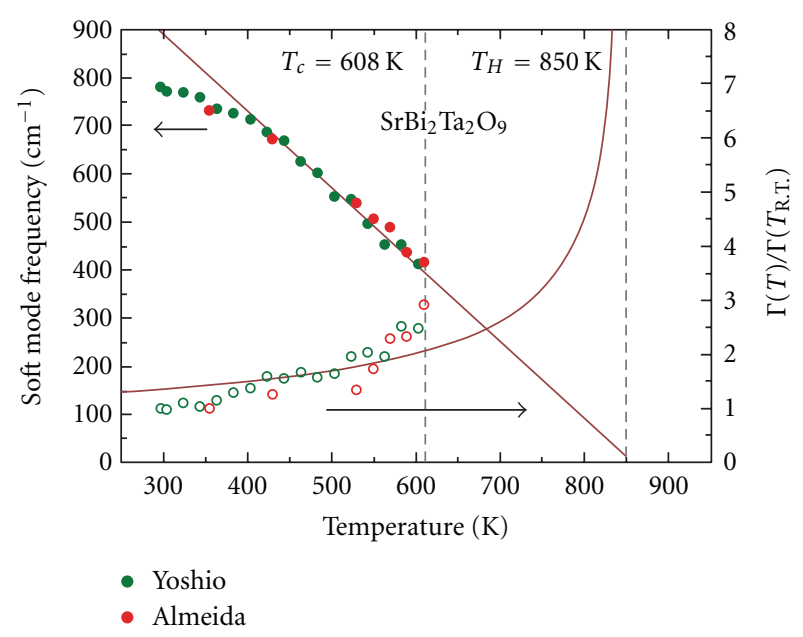

FIgURE 13: Temperature dependence of soft mode frequency (square of Raman frequency shift) and a normalized damping factor $\Gamma(T) / \Gamma\left(T_{\text {R.T. }}\right)$ in $\mathrm{SrBi}_{2} \mathrm{Ta}_{2} \mathrm{O}_{9}$ [31-33].

The square of soft mode frequency decreases toward the highest phase transition temperature $(850 \mathrm{~K})$ and shows a clear anomaly at $610 \mathrm{~K}\left(T_{c}\right)$. The soft mode exists in the ferroelectric phase and shows highly overdamped behavior near $T_{c}$, although dielectric constant does not diverse at $T_{c}$. Another anomaly was detected in the share strain $c_{44}$ at $850 \mathrm{~K}$ [46], which corresponds to the high-temperature phase transition at $850 \mathrm{~K}$.

A series of Bi-layered perovskites compounds $\mathrm{Bi}_{2 m} \mathrm{~A}_{n-m} \mathrm{~B}_{n} \mathrm{O}_{3(n+m)}$ were synthesized by Aurivillius in 1949 [47]. As $\mathrm{Sr}_{2} \mathrm{Bi}_{4} \mathrm{Ti}_{5} \mathrm{O}_{18}$ is a compound with five perovskite layers with $\mathrm{Bi}_{2} \mathrm{O}_{2}$ semiconducting layers as shown in Figure 14, it is considered as a model of perovskite thin film with five unit cells. This crystal undergoes a ferroelectric phase transition at $558 \mathrm{~K}$, although it has been reported that the ferroelectricity of thin films may be suppressed below six unit cells after Junquera and Ghosez [29]. In this compound, similar dielectric properties as those observed in SBT have been reported. The spontaneous polarization appears along the $a$ axis and the dielectric constant shows rather weak temperature dependence. In $\mathrm{Sr}_{2} \mathrm{Bi}_{4} \mathrm{Ti}_{5} \mathrm{O}_{18}$, similar temperature dependence of soft mode was observed by Raman scattering [33]. Raman spectra showed two anomalies at $551 \mathrm{~K}$ and at $730 \mathrm{~K}$. The soft mode frequency decreases toward $730 \mathrm{~K}$, although it shows overdamped behavior over $450 \mathrm{~K}$. Furthermore, two additional relaxation modes have been observed, which show an anomaly at $551 \mathrm{~K}$. Even in the case of SBT $(m=2)$ and $\mathrm{Sr}_{2} \mathrm{Bi}_{4} \mathrm{Ti}_{5} \mathrm{O}_{18}$ $(m=5)$, the soft mode still exists, although it becomes highly overdamped near $T_{c}$.

\section{Summary and Discussion}

Bi-layered perovskites have been much attracted as a promising material for ferroelectric integrated devices. According to the calculations of local field by Luttinger and Tisza [48], the strong ferroelectric interaction between $\mathrm{Ti}$ (or $\mathrm{Ta}$ ) ion and $\mathrm{O}$ ions appears along the tetragonal $c$ axis. Although the

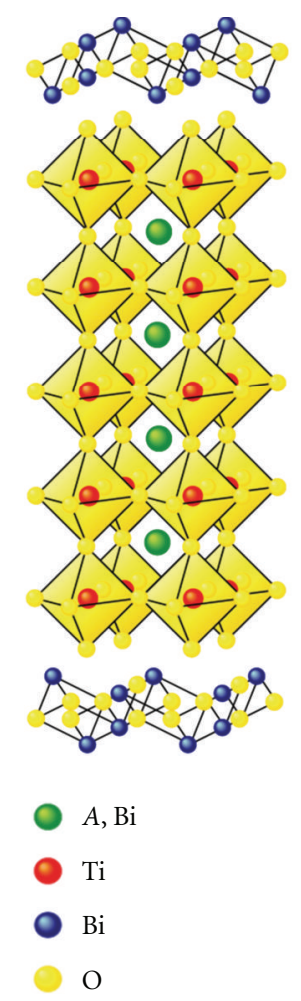

Figure 14: Crystal structure of Bi-layered perovskite $\mathrm{A}_{2} \mathrm{Bi}_{4} \mathrm{Ti}_{5} \mathrm{O}_{18}$ with $m=5$.

strongly correlated -O-Ti-O-Ti-O- chain plays an important role for the appearance of ferroelectricity in bulk $\mathrm{BaTiO}_{3}$ [26], the -O-Ta-O-Ta-O- chain along the pseudo-tetragonal $c$ axis is interrupted by the existence of semiconductor $\mathrm{Bi}_{2} \mathrm{O}_{2}$ layers in SBT. The strength of interaction between $\mathrm{Ti}$ ion and adjacent $\mathrm{O}$ ions is half, but antiferroelectric in the $a-b$ plane. However, the configuration of distortion parameter $p$ in Figure 12 suggests us that the interaction is strong but antiferroelectric along the pseudotetragonal $c$ axis, and ferroelectric along the $a$ axis in SBT. It is expected that a crossover of ferroelectric to antiferroelectric interaction will be realized even in thin films of $\mathrm{BaTiO}_{3}$, considering the similarity of dielectric properties between SBT bulk crystal and thin $\mathrm{BaTiO}_{3}$ films mentioned above. In this sense, SBT bulk crystals may be considered as a model of ferroelectric thin films. It might be expected that the cant of dipole moments may be induced even in thin $\mathrm{BaTiO}_{3}$ films by the two-dimensionality.

The suppression of ferroelectricity has been reported for nano-particles of $\mathrm{BaTiO}_{3}$ and $\mathrm{PbTiO}_{3}$, where the critical size is $20 \sim 30$ unit cells [49]. However, the dipole-dipole interactions within plane are retained and contribute to ferroelectric activity in the case of thin films.

The dielectric and structural analogy between $\mathrm{SrBi}_{2} \mathrm{Ta}_{2} \mathrm{O}_{9}$ and thin film suggests that this bulk layered ferroelectric is a good model of ultra-thin ferroelectric films with two layers of $\mathrm{TaO}_{6}$ perovskite units, free from any misfit lattice strain with substrate and surface charge at the interface with electrodes. In perovskite ultra-thin films, ferroelectric 
interactions are still prominent and the octahedra prefer an antiferroelectric arrangement rather than ferroelectric one along the tetragonal axis (normal to the plane) in the case of two layers. The soft mode exists but changes to be highly over damped near the ferroelectric phase transition temperature. Moreover, the mechanism mentioned above might be applicable for $\mathrm{Sr}_{2} \mathrm{Bi}_{4} \mathrm{Ti}_{5} \mathrm{O}_{18}$ with five perovskite groups $(m=5)$, because the almost same dielectric behavior has been observed in $\mathrm{Sr}_{2} \mathrm{Bi}_{4} \mathrm{Ti}_{5} \mathrm{O}_{18}$ which has perovskite units less than six unit cells. Further experiments will be necessary both in layered oxide ferroelectrics and perovskite thin films.

\section{References}

[1] W. Cochran, "Crystal stability and the theory of ferroelectricity," Advances in Physics, vol. 9, pp. 387-423, 1960.

[2] W. Cochran, "Crystal stability and the theory of ferroelectricity part II. Piezoelectric crystals," Advances in Physics, vol. 10, pp. 401-420, 1961.

[3] C. A.-P. de Marajo, J. D. Cushier, L. D. McMillan et al., "Fatigue-free ferroelectric capacitors with platinum electrodes," Nature, vol. 374, pp. 627-629, 1995.

[4] J. F. Scott, "NANO-phase SBT-family ferroelectric memories," Ferroelectrics Review, vol. 1, pp. 1-14, 1998.

[5] M. Dauber, K. M. Raba, and J. F. Scott, "Physics of thin-film ferroelectric oxides," Reviews of Modern Physics, vol. 77, pp. 1083-1130, 2005.

[6] G. A. Smolenskii, V. A. Isupov, and A. I. Agranovskaya, "Ferroelectrics of the oxygen-octahedral type with layered structure," Soviet Physics, vol. 3, no. 3, pp. 651-655, 1961.

[7] Y. Yoneda, H. Kasatani, H. Terauchi, Y. Yano, T. Terashima, and Y. Bando, "Ferroelectric phase transition in $\mathrm{BaTiO}_{3}$ films," Journal of the Physical Society of Japan, vol. 62, no. 6, pp. 1840 1843, 1993.

[8] K. Yoshio, A. Onodera, and H. Yamashita, "Ferroelectric phase transition and new intermediate phase in Bi-layered perovskite $\mathrm{SrBi}_{2} \mathrm{Ta}_{2} \mathrm{O}_{9}$," Ferroelectrics, vol. 284, no. 1, pp. 65-74, 2003.

[9] E. C. Subbarao, "A family of ferroelectric bismuth compounds," Journal of Physics and Chemistry of Solids, vol. 23, no. 6, pp. 665-676, 1962.

[10] A. Onodera, K. Yoshio, C. C. Myint, S. Kojima, H. Yamashita, and T. Takama, "Thermal and structural studies of phase transitions in layered perovskite $\mathrm{SrBi}_{2} \mathrm{Ta}_{2} \mathrm{O}_{9}$," Japanese Journal of Applied Physics B, vol. 38, no. 9, pp. 5683-5685, 1999.

[11] A. Onodera, T. Kubo, K. Yoshio, S. Kojima, H. Yamashita, and T. Takama, "Crystal structure of high-temperature paraelectric phase in Bi-layered perovskite $\mathrm{Sr}_{0.85} \mathrm{Bi}_{2.1} \mathrm{Ta}_{2} \mathrm{O}_{9}$," Japanese Journal of Applied Physics B, vol. 39, no. 9, pp. 5711-5715, 2000.

[12] A. Onodera, K. Yoshio, C. C. Myint et al., "Thermal behavior in ferroelectric $\mathrm{SrBi}_{2} \mathrm{Ta}_{2} \mathrm{O}_{9}$ thin films," Ferroelectrics, vol. 241, pp. 159-166, 2000.

[13] W. Murata, A. Onodera, K. Yoshio et al., "Ferroelectric phase transition in layered perovskite $\mathrm{SrBi}_{2} \mathrm{Ta}_{2} \mathrm{O}_{9}$," Ferroelectrics, vol. 270, no. 1, pp. 303-308, 2002.

[14] A. Onodera, K. Yoshio, and H. Yamashita, "Structural study of intermediate phase in layered perovskite $\mathrm{SrBi}_{2} \mathrm{Ta}_{2} \mathrm{O}_{9}$ single crystal," Japanese Journal of Applied Physics, vol. 42, pp. 6218 6221, 2003.

[15] H. Terauchi, Y. Yoneda, Y. Watanabe et al., "Epitaxial $\mathrm{BaTiO}_{3}$ crystals," Ferroelectrics, vol. 151, no. 1, pp. 21-26, 1994.
[16] Y. Yoneda, H. Kasatani, H. Terauchi, Y. Yano, T. Terashima, and Y. Bando, "Ferroelectric phase transition in $\mathrm{BaTiO}_{3}$ films," Journal of Crystal Growth, vol. 150, no. 1, pp. 1090-1093, 1995.

[17] K. Iijima, T. Terashima, Y. Bando, K. Kamigaki, and H. Terauchi, "Atomic layer growth of oxide thin films with perovskite-type structure by reactive evaporation," Journal of Applied Physics, vol. 72, no. 7, pp. 2840-2845, 1992.

[18] Y. Yano, K. Iijima, Y. Daitoh et al., "Epitaxial growth and dielectric properties of $\mathrm{BaTiO}_{3}$ films on Pt electrodes by reactive evaporation," Journal of Applied Physics, vol. 76, no. 12, pp. 7833-7838, 1994.

[19] A. K. Tagantsev, N. A. Pertsev, P. Muralt et al., "Strain-induced diffuse dielectric anomaly and critical point in perovskite ferroelectric thin films," Physical Review B, vol. 65, Article ID 012104, 4 pages, 2001.

[20] S. Grabovsky, M. Takesada, A. Onodera et al., "Specific heat and light scattering data of barium titanate crystals near ferroelectric phase transition," in Abstract of Annual Meeting of Physical Society of Japan, Kansei-Gakuin University, March 2012.

[21] A. Onodera, Y. Kawamura, T. Okabe, and H. Terauchi, "Specific heat in ferroelectric $\mathrm{BaTiO}_{3}$ epitaxial thin films," Journal of the European Ceramic Society, vol. 19, no. 6-7, pp. 14771480, 1999.

[22] B. A. Strukov, S. T. Davitadze, S. A. Taraskin et al., "Thermodynamical properties of the thin polycrystalline $\mathrm{BaTiO}_{3}$ films on substrates," Ferroelectrics, vol. 286, pp. 245-250, 2003.

[23] S. T. Davitadze, S. N. Kravchun, B. A. Strukov, B. M. Goltzman, V. V. Lemanov, and S. G. Shulman, "Specific heat and thermal conductivity of $\mathrm{BaTiO}_{3}$ polycrystalline thin films," Applied Physics Letters, vol. 80, no. 9, pp. 1631-1633, 2002.

[24] H. Terauchi, Y. Watanabe, H. Kasatani et al., "Structural study of epitaxial $\mathrm{BaTiO}_{3}$ crystals," Journal of the Physical Society of Japan, vol. 61, no. 7, pp. 2194-2197, 1992.

[25] H. Yamashita, K. Yoshio, W. Murata et al., "Structural changes and ferroelectricity in bi-layered $\mathrm{SrBi}_{2} \mathrm{Ta}_{2} \mathrm{O}_{9}$," Japanese Journal of Applied Physics, vol. 41, pp. 7076-7079, 2002.

[26] J. C. Slater, "The lorentz correction in barium titanate," Physical Review, vol. 78, pp. 748-761, 1950.

[27] H. Terauchi, Y. Watanabe, H. Kasatani et al., "X-Ray studies on single crystal films of $\mathrm{BaTiO}_{3}$," Ferroelectrics, vol. 137, pp. 33-38, 1992.

[28] M. E. Lines and A. M. Glass, Principles and Applications of Ferroelectrics and Related Materials, Clarendon Press, Oxford, UK, 1977.

[29] J. Junquera and P. Ghosez, "Critical thickness for ferroelectricity in perovskite ultrathin films," Nature, vol. 422, no. 6931, pp. 506-509, 2003.

[30] D. A. Tenne, P. Turner, J. D. Schmidt et al., "Ferroelectricity in ultrathin $\mathrm{BaTiO}_{3}$ films: probing the size effect by ultraviolet raman spectroscopy," Physical Review Letters, vol. 103, no. 17, Article ID 177601, 2009.

[31] K. Yoshio, I. Matsubara, A. Yamada et al., "Phase transition in ferroelectric $\mathrm{SrBi}_{2} \mathrm{Ta}_{2} \mathrm{O}_{9}$ single crystal," Journal of Korean Physics Society, vol. 43, p. S1034, 2003.

[32] A. Almeida, M. R. Chaves, H. Amorin, M. E. V. Costa, and A. L. Kholkin, "Lattice dynamics study of high-quality strontium bismuth tantalate single crystals," Journal of Physics Condensed Matter, vol. 17, no. 48, pp. 7605-7612, 2005.

[33] M. Fukunaga, "Soft mode and relaxation behavior in twodimensional ferroelectric Bi-layered perovskites," [Ph.D. thesis], HokkaidoUniversity, 2009. 
[34] K. Miura, "Electronic properties of ferroelectric $\mathrm{SrBi}_{2} \mathrm{Ta}_{2} \mathrm{O}_{9}$, $\mathrm{SrBi}_{2} \mathrm{Nb}_{2} \mathrm{O}_{9}$, and $\mathrm{PbBi}_{2} \mathrm{Nb}_{2} \mathrm{O}_{9}$ with optimized structures," Applied Physics Letters, vol. 80, p. 2967, 2002.

[35] Y. Shimakawa, Y. Kubo, Y. Nakagawa et al., "Crystal structures and ferroelectric properties of $\mathrm{SrBi}_{2} \mathrm{Ta}_{2} \mathrm{O}_{9}$ and $\mathrm{Sr}_{0.8} \mathrm{Bi}_{2.2} \mathrm{Ta}_{2} \mathrm{O}_{9}$ ," Applied Physics Letters, vol. 74, p. 1904, 1998.

[36] A. D. Rae, J. G. Thompson, and R. L. Withers, "Structure refinement of commensurately modulated bismuth strontium tantalate, $\mathrm{Bi}_{2} \mathrm{SrTa}_{2} \mathrm{O}_{9}$," Acta Crystallographica B, vol. 48, pp. 418-428, 1992.

[37] T. Tybell, C. H. Ahn, and J. M. Triscone, "Ferroelectricity in thin perovskite films," Applied Physics Letters, vol. 75, no. 6, pp. 856-858, 1999.

[38] A. V. Bune, V. M. Fridkin, S. Ducharme et al., "Two-dimensional ferroelectric films," Nature, vol. 391, no. 6670, pp. 874$877,1998$.

[39] B. Meyer and D. Vanderbilt, "Ab initio study of $\mathrm{BaTiO}_{3}$ and $\mathrm{PbTiO}_{3}$ surfaces in external electric fields," Physical Review B, vol. 63, Article ID 205426, 2001.

[40] Ph. Ghosez and K. M. Rabe, "Microscopic model of ferroelectricity in stress-free $\mathrm{PbTiO}_{3}$ ultrathin films," Applied Physics Letters, vol. 76, p. 2767, 2000.

[41] T. Moriya, "Weak ferromagnetism," in Magnetism, G. T. Rado and H. Suhl, Eds., vol. 1, p. 85, Academic Press, New York, NY, USA, 1963.

[42] P.-G. de Gennes, "Effects of double exchange in magnetic crystals," Physical Review B, vol. 118, pp. 141-154, 1960.

[43] C. Kittel, "Theory of antiferroelectric crystals," Physical Review, vol. 82, pp. 729-732, 1951.

[44] C. S. Hwang, "Thickness-dependent dielectric constants of $(\mathrm{Ba}, \mathrm{Sr}) \mathrm{TiO}_{3}$ thin films with $\mathrm{Pt}$ or conducting oxide electrodes," Applied Physics, vol. 92, p. 432, 2002.

[45] J.-H. Ko, A. Hushur, S. Kojima et al., "Acoustic anomalies and central peak in $\mathrm{SrBi}_{2} \mathrm{Ta}_{2} \mathrm{O}_{9}$ single crystals studied by microBrillouin scattering," Applied Physics Letters, vol. 81, p. 4043, 2002.

[46] M. Takesada, K. Sutoh, M. Fukunaga, and A. Onodera, "Light scattering study of bismuth layered ferroelectric $\mathrm{SrBi}_{2} \mathrm{Ta}_{2} \mathrm{O}_{9}$," Ferroelectrics, vol. 355, no. 1, pp. 149-153, 2007.

[47] B. Aurivillius, "Mixed bismuth oxides with layer lattices I. The structure type of $\mathrm{CaNb}_{2} \mathrm{Bi}_{2} \mathrm{O}_{9}$," Arkkitehtuuritoimisto, vol. 1, p. 893, 1949.

[48] J. M. Luttinger and L. Tisza, "Theory of dipole interaction in crystals," Physical Review, vol. 72, no. 3, p. 257, 1947.

[49] K. Ishikawa, T. Nomura, N. Okada et al., "Size effect on the phase transition in PbTiO3 fine particles," Japanese Journal of Applied Physics, vol. 35, pp. 5196-5198, 1996. 

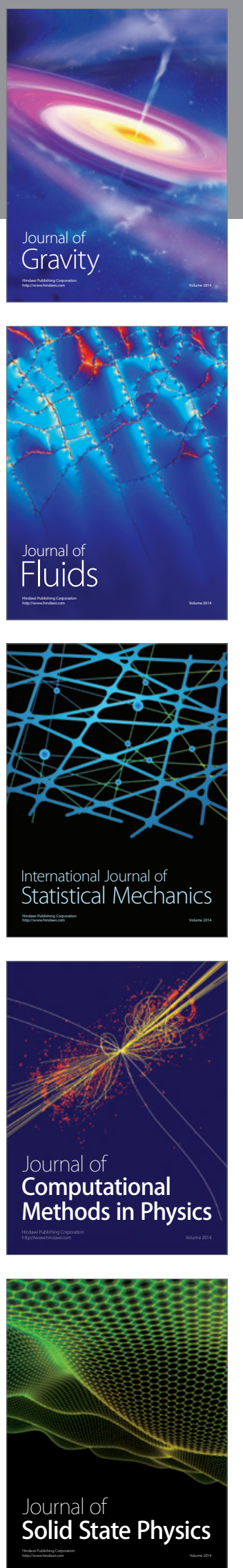

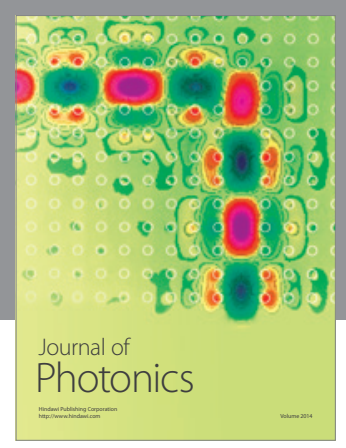

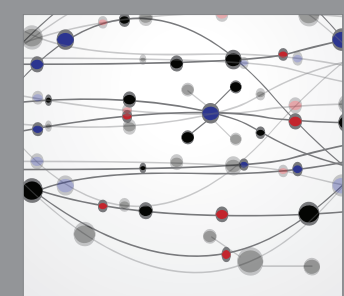

The Scientific World Journal
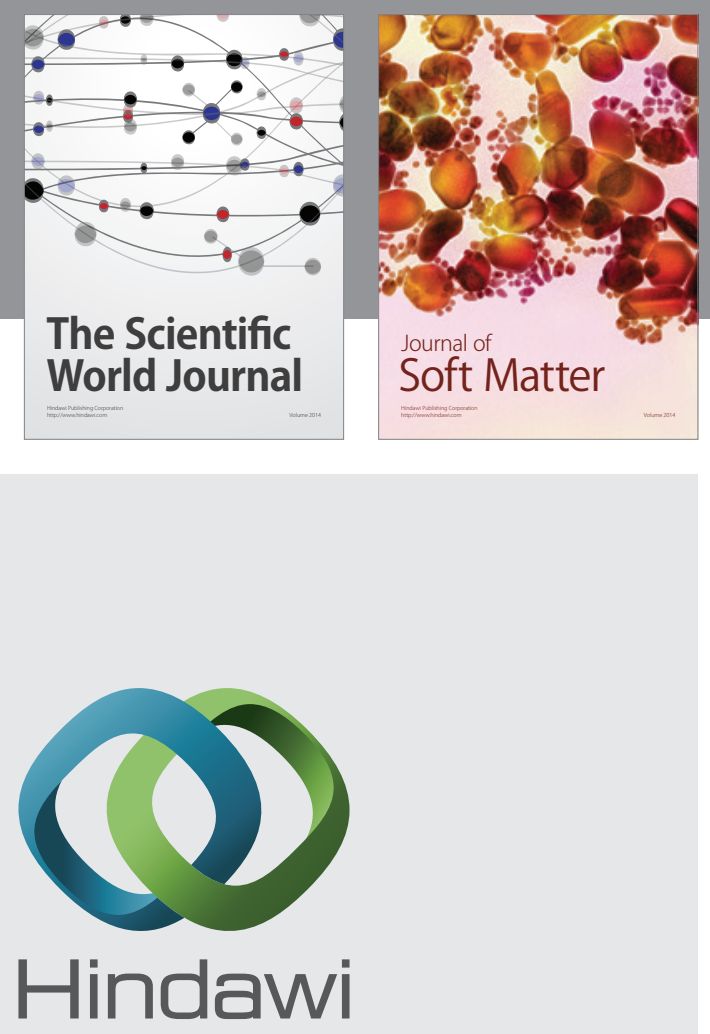

Submit your manuscripts at

http://www.hindawi.com
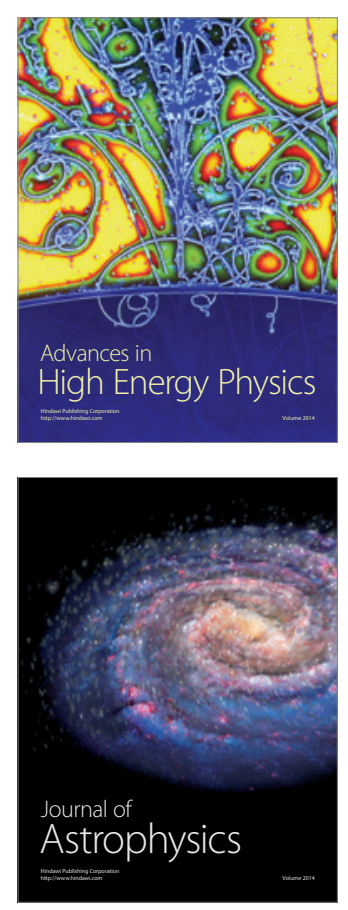
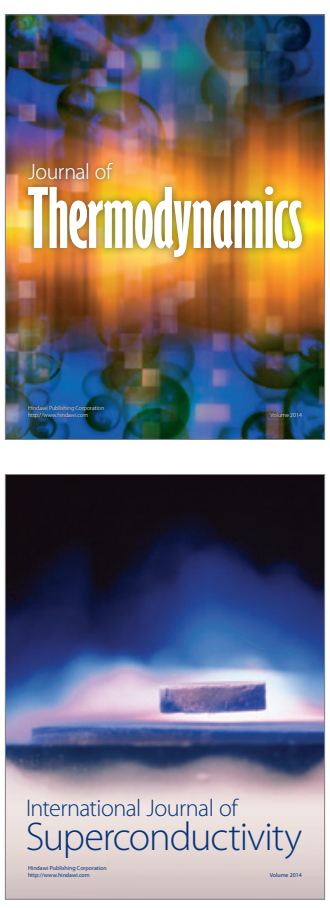
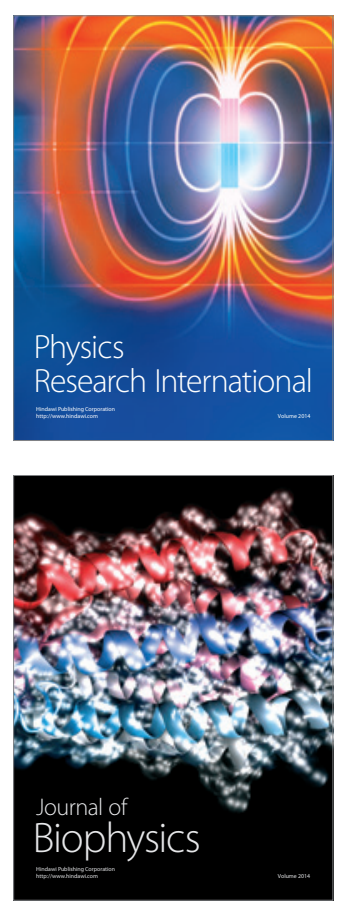
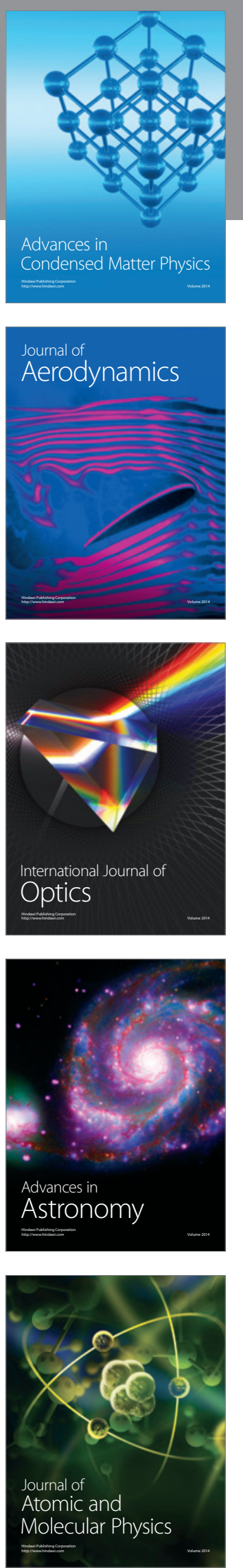